\title{
Configurações
}

Revista de sociologia

\section{Epistemologias do Sul. Contextos de investigação}

\section{Sheila Khan e Rita Ribeiro}

\section{(2) OpenEdition \\ Journals}

\section{Edição electrónica}

URL: http://journals.openedition.org/configuracoes/2197

DOI: 10.4000/configuracoes.2197

ISSN: 2182-7419

\section{Editora}

Centro de Investigação em Ciências Sociais

\section{Edição impressa}

Data de publição: 1 Dezembro 2013

ISBN: 1646-5075

ISSN: 1646-5075

\section{Refêrencia eletrónica}

Sheila Khan e Rita Ribeiro, « Epistemologias do Sul. Contextos de investigação », Configurações [Online], 12 | 2013, posto online no dia 20 novembro 2014, consultado o 06 maio 2019. URL : http:// journals.openedition.org/configuracoes/2197 ; DOI : 10.4000/configuracoes.2197

Este documento foi criado de forma automática no dia 6 Maio 2019.

(c) CICS 


\title{
Epistemologias do Sul. Contextos de investigação
}

\author{
Sheila Khan e Rita Ribeiro
}

1 Este número temático ${ }^{1}$ é dedicado a refletir acerca das Epistemologias do Sul como enquadramento teórico e metodológico para pensar, em termos metafóricos, o 'Sul' - o 'Sul' como espaço social e cultural periférico no contexto das experiências coloniais, imperiais e de exploração capitalista nos territórios colonizados pelas potências europeias. Mas, em paralelo a esse objetivo, trata-se de pensar e dialogar com um 'Sul' socialmente produzido como ausente, inexistente, incapaz e marginal na possibilidade de se imaginar como fonte produtora de conhecimentos sociais no mundo quer global, quer local. Remetido ao esquecimento por rotinas diversas e ancoradas em pensamentos hegemónicos europeus e, especialmente, nórdicos, o 'Sul' tende a representar, num limiar crítico, todos os fenómenos sociais, culturais, educativos e históricos que são colocados na periferia de um pensamento padrão, por definirem como alternativas metas de trabalho e de reflexão que rompem a subordinação de uns saberes perante outros saberes. A recusa de uma subjugação epistemológica em prol de uma reflexão mais proactiva e vigilante serve de húmus a este volume.

2 Os trabalhos apresentados neste volume congregam em si a força e o sentido de refl exão crítica que subjaz à filosofia e praxis das Epistemologias do Sul. Maria Paula Meneses, em "Para ampliar as Epistemologias do Sul: verbalizando sabores e revelando lutas", oferece ao leitor uma análise etnográfica dos vários contextos cultural e historicamente contrastantes em função de um sistema de hierarquias entre saberes, sabores, lutas e narrativas sociais que traduzem as guerras entre nações e entre soberanias que se impõem a um custo tão elevado que, como observa a autora, levam a uma exaustão do sistema de pensamento vigente, o pensamento de cariz ocidental. Apropriando com cuidado e fazendo emergir no seu texto detalhes, paisagens e avatares históricos e culturais, Paula Meneses torna visível e como objeto de investigação e de análise a importância da cozinha, que se constitui como um imenso laboratório que nos interroga sobre como e de onde interpelamos o mundo, na procura de ligações epistemológicas e estéticas. Para lá de um modelo de olhar o mundo de uma maneira limitada e 
monocultural, a autora deste texto demonstra com grande propriedade o potencial imenso para ampliar a ecologia de saberes, partindo de desafios colocados pelas críticas pós-coloniais e das Epistemologias do Sul.

3 A discussão teórica sobre esta temática prossegue com o artigo de Sandra Sousa e Tom Lewis, que estabelece um estimulante diálogo crítico com a introdução à obra Another Knowledge is Possible: Beyond Northern Epistemologies, de Boaventura de Sousa Santos et al. Os autores deste artigo problematizam as propostas dos sociólogos portugueses, e dos estudos pós-coloniais em geral, desafiando a conceção binária Norte-Sul e os equívocos das 'políticas' de identidade' que a sustentam. Em alternativa, retomam as potencialidades do pensamento marxista na contestação do modelo económico global hegemónico - o capitalismo - e na acção emancipatória dos que, a Norte e a Sul, são por ele explorados e alienados.

4 Beatriz Padilla e Thais França interpelam-nos com uma reflexão interventiva e crítica do contexto de investigação português, no que concerne as suas forças subterrâneas de cariz cultural e discriminatório. Em "Epistemologias feministas e mobilidade científica: contribuições para o debate", as autoras provocam o leitor com um timbre intimista, mas seriamente comprometido com um sentido minucioso de pensar os caminhos difíceis e subtis dos mundos abissais dos atores e sujeitos produtores de conhecimento. Partindo de um ponto de vista feminista, as autoras procuram legitimar e defender o campo de produção científica feito e consumado por mulheres, que são simultaneamente cientistas, pensadoras, imigrantes e cidadãs de nacionalidade estrangeira. $\mathrm{E}$, ao mesmo tempo, visam com veemência reclamar o carácter político da produção de conhecimento ao denunciar o androcentrismo, o colonialismo, o universalismo e o eurocentrismo sobre os quais a ciência moderna e ocidental assenta.

5 No seu artigo "A cegueira em Moçambique: a Sul de um sentido", Bruno Sena Martins apresenta um olhar comparativo sobre como a cegueira é representada e vivida em sistemas culturais opostos e como diferentes epistemologias geram diferentes saberes, ontologias e interpretações no que respeita ao seu objeto de estudo. Este trabalho parte de uma incursão etnográfica em Moçambique ao encontro das pessoas cegas, no qual o autor analisa as implicações de uma concepção de cegueira intimamente ligada às dinâmicas socioespirituais, observando nestas indagações, cotejadas com as interpretações da cegueira a partir da sua história no Ocidente, a forma como a cegueira é sentida, vivida e interpretada de forma tão diversa - na verdade, a forma como a cegueira é retratada dependendo dos seus contextos sociais, culturais, históricos e políticos.

6 Comprovando a influência perniciosa e asfixiante de um modelo de cariz ocidental sobre os estudos culturais, Rosa Cabecinhas e João Feijó apresentam, em "Representações sociais do processo social - Perspectivas cruzadas entre estudantes moçambicanos e portugueses", dados que remetem o leitor para uma realidade pejada de "espaços brancos', por uma História ainda assaz arreigada a uma visão parcial da diversidade cultural e humana: nela o 'Norte' tende a ser representado como o motor da história, ao passo que o 'Sul' é remetido ao esquecimento. Nesse sentido, argumentam os autores, as representações sociais da história veiculadas pelos media e disseminadas nas enciclopédias ditas globais são talvez um dos mais evidentes exemplos do quanto ainda há a fazer para descolonizar o pensamento.

7 Em "Caminhos desobedientes: Pensar criticamente o contexto português de Conhecimento", Sheila Khan e José Morgado recuperam o enunciado da urgência de uma maior vigilância face ao desafio de 'descolonizar o pensamento'. Para tal, os autores 
procuram pensar de uma maneira crítica a construção, a difusão e a validação do currículo. As reflexões pelos autores aqui apresentadas constituem uma leitura analítica, no sentido de demonstrar que a construção dos currículos e seus produtos finais, tais como os manuais escolares, permanecem como ferramentas e dispositivos ainda ancorados numa lógica de pensamento ocidental, monocultural e limitado na sua visão cultural da experiência humana.

Vítor de Sousa apresenta uma densa desconstrução conceptual de topos centrais da identidade portuguesa contemporânea - lusofonia e portugalidade. Analisando os equívocos e contradições inerentes à ideia de lusofonia, enquanto categoria política e cultural, o texto discute a sua compatibilidade com o Portugal pós-colonial, dado o lusocentrismo latente e a estreita relação com a noção de portugalidade que, ao retomar as narrativas imperiais, coarcta relações de reciprocidade com as culturas do designado 'espaço lusófono'.

9 Tal como evidenciam os textos de Ana Margarida Fonseca e Emmanuele Santos, são muitos os contextos de investigação por que perpassam estes fossos abissais e ambiguidades de um mundo ainda remanescente, este do passado-presente colonial, mascarado por outras formulações e chavões como neocolonialismo, multiculturalismo, globalização, e tão sedutor nos seus prefixos com maior protagonismo para o póscolonialismo. Estes exemplos tornam-se claros nos estudos literários, onde as várias cartografias literárias e culturais manifestam, por um lado, a sua vontade de emancipação e, por outro, a sua consciência de uma permanente existência de proximidades culturais, semânticas, afetivas e históricas, que não devem ser descuradas e olvidadas, em prol de uma maior riqueza e pluri-vidência das literaturas em língua portuguesa. Ana Margarida Fonseca parte do enunciado de um maior descentramento do olhar, partindo do questionamento do conceito de lusofonia e das suas ambiguidades, para, desse modo, propor uma reflexão bem contextualizada do papel da língua portuguesa e das literaturas que nela se exprimem no contexto de um pós-colonialismo situado. É nesse caminho da pluralidade, e de um lugar que historicamente possa ser de partilha e convivência, que Emanuelle Santos traz, no seu trabalho "O pós-colonial entre Norte e Sul: formulações teóricas, implicações políticas na batalha pela 'arma da teoria”, um alerta para os perigos de uma teoria pós-colonial na qual possam vir disfarçadas, ainda, as ferramentas de um sistema de subjugação e de subalternidades. Se, a teoria pós-colonial é analisada como uma saudável vantagem face ao passado, importa, contudo - alerta a autora - atentar para possíveis continuidades da lógica colonial inerente à própria dialética entre as noções de centro e periferia, quando evocada por uma crítica às literaturas africanas escritas em português, localizada principalmente em Portugal e no Brasil.

Atenta a esta continuidade da lógica colonial, Jessica Falconi foca, no seu artigo "Ler o Sul. Os estudos de literaturas africanas em Portugal na década de 80" alguns aspetos do desenvolvimento crítico relativo às literaturas africanas de língua portuguesa, com enfoque especial na literatura moçambicana, a partir de textos críticos da década de 1980, época em que se consolida a institucionalização desta disciplina nas universidades portuguesas. Kamila Krakowska, em "Entre o passado tradicional e o futuro socialista: as modernidades moçambicanas em Terra Sonâmbula, de Mia Couto", retoma com grande elegância os momentos que simbolizam os diferentes paradigmas de modernidade que Moçambique experienciou no período pós-independência, quando em si vivia de uma maneira brutal a guerra civil. Como observa a autora, este trabalho tem como preocupação a desconstrução de vários pressupostos e estereótipos relacionados com os 
conceitos de tradição e modernidade, frequentemente apresentados como binarismos, no caminho da construção de Moçambique como nação.

11 Eunice Seixas, num texto de cariz teórico, analisa as políticas de ensino superior no espaço europeu, designadamente os processos de internacionalização e de privatização. Recorrendo aos dispositivos conceptuais dos estudos pós-coloniais e da análise crítica do discurso, a autora discute a mercadorização do ensino superior na Europa, num quadro político-ideológico dominado pelos ditames do neoliberalismo, e a desconstrução e a resistência urgentes das políticas da educação de nível superior.

12 A encerrar o conjunto de artigos que compõem este número temático, Rui Vieira Cruz desenvolve uma reflexão original sobre o modo como o paradigma nanotecnológico é integrado nos videojogos, operacionalizando na sua análise a questão da hegemonia do Norte global. A partir da indústria cultural dos videojogos, o autor revela como nestes produtos de entretenimento se reproduzem as fissuras Norte-Sul e as linhas de força que promovem a desqualificação do Sul global através de representações de debilidade e passividade.

13 Este número conta ainda com um conjunto de recensões que sugerem leituras de obras recentemente publicadas, abordando contextos de investigação estreitamente ligados à temática desta publicação.

\section{NOTAS}

1. Para além dos textos recebidos na sequência da chamada de trabalhos, uma parte importante dos artigos resulta do contributo de autores que participaram no seminário que se realizou no Instituto de Ciências Sociais, em junho de 2013, intitulado "Caminhos Desobedientes: Refl etir o 'Sul' no Contexto Português de Investigação". Esse encontro, organizado pelo Centro de Investigação em Ciências Sociais (CICS), o Centro de Estudos de Comunicação e Sociedade (CECS) e Centro de Investigação Interdisciplinar Cultura, Espaço e Memória (CITCEM), constituiu a matriz inspiradora do presente número.

\section{AUTORES}

RITA RIBEIRO 